Pacific Journal of Mathematics

ON FUNDAMENTAL PROPERTIES OF A BANACH SPACE 


\section{ON FUNDAMENTAL PROPERTIES OF A BANACH SPACE WITH A CONE}

\section{T. ANDô}

1. Introduction. Normed vector lattices have been investigated from various angles (see [1] Chap. 15 and [7] Chap. 6). On the contrary, it seems that there remain several problems unsolved in the theory of general normed spaces with a cone since the pioneer works of Riesz and Krein, though recently Namioka [8], Schaefer [9] and others made many efforts in analysing and extending the results of Riesz and Krein. In this paper we shall discuss two among them. Let $E$ be a Banach space with a closed cone $K$ (for the terminologies see $\S 2$ );

(A) What condition on the dual $E^{*}$ is necessary and sufficient for that $E=K-K$ ?

(B) What condition on the dual is necessary and sufficient for the interpolation property of $E$ ?

Grosberg and Krein [3] dealt with (A) in a reversed form;

(A') What condition on $E$ is necessary and sufficient for that $E^{*}=$ $K^{*}-K^{*}$ where $K^{*}$ is the dual cone?

Schaefer ([9], Th. 1.6) obtained a complete answer to $\left(\mathrm{A}^{\prime}\right)$ within a scope of locally convex spaces. A result of Riesz gives a half of an answer to (B), while Krein [6] obtained a complete answer only under the assumption that the cone has an inner point.

The purpose of this paper is to give answers to both (A) and (B) in natural settings. Our starting assumptions consist of the completeness of $E$ and of the closedness of the cone $K$.

After several comments on order properties in $\S 2$, Lemmas in $\S 3$ present algebraic forms to both the property named normality by Krein [5] and that named (BZ)-property by Schaefer [9], supported by Banach's open mapping theorem. Then Theorem 1 will produce an answer to (A) via these Lemmas. $\S 4$ is devoted to an answer to (B) under the condition that $E$ is an ordered Banach space. It should be remarked that our main theorems are also valid for $(F)$ spaces, that is, metrisable complete locally convex spaces.

2. Definitions and consequences. Let $E^{1}$ be a real normed space and let $K$ be a cone, that is, a subset of $E$ with the following properties:

(1) $K+K \subset K$,

(2) $\alpha K \subset K$ for all $\alpha \geqq 0$, and

Received February 8, 1962.

1 Elements of $E$ are denoted by $x, y, a, \cdots, e$, and those of the dual $E^{*}$ by $f, g, h$. Scalars are denoted by Greek letters. $\theta$ is reserved for the zero element. 
(3) $K \cap(-K)=\{\theta\}$. Then the natural partial ordering $\geqq$ is associated with the cone $K$, i.e. $a \geqq b$ in case $a-b \in K$. A subset of the form $\{x ; a \leqq x \leqq b\}$ will be called an interval. The dual $E^{*}$ of $E$ is also partially ordered by the dual cone $K^{*} \stackrel{\text { def }}{=}\left\{f \in E^{*} ; f(x) \geqq 0\right.$ for all $x \in K$ \}, though $K^{*}$ does not always satisfy the condition (3). ${ }^{2}$

The cone $K$ is said to generate $E$ or to be a generating cone in case every element in $E$ can be written as difference of two in $K$, that is, $E=K-K . \quad E$ is said to have the interpolation property with respect to $\geqq$ in case $a, b \geqq c, d$ implies the existence of $x$ such that $a, b \geqq x \geqq c, d$. This property is equivalent to the following one named the decomposition property: whenever $a, b, x \in K$ and $a+b \geqq x$, there exist $c, d \in K$ such that $x=c+d, a \geqq c$ and $b \geqq d$. When for any pair $a, b \in E$ there exists the supremum $a \vee b, E$ is called a vector lattice. A vector lattice has the interpolation property and its cone is generating.

There are several notions connected with the so-called order topology. $E$ is said to be (o)-complete in case any upward directed subset with an upper bound (with respect to $\geqq$ ) has the supremum. When the directed subset in question is restricted to that consisting of countable members, $E$ is said to be $\sigma$-(o)-complete. As a less restrictive completeness, $E$ is said to be quasi-(o)-complete in case any sequence $\left\{a_{i}\right\}$, such that $\theta \leqq$ $a_{1} \leqq a_{2} \leqq \cdots \leqq a$ and $a_{i+j}-a_{i} \leqq \varepsilon_{i} a$ with $\varepsilon_{i} \downarrow 0$, has the supremum. In many cases $(o)$-completeness can be derived from $\sigma$-(o)-completeness. It is clear that if $E$ with the generating cone is $(o)$-complete and has the interpolation property, it is a vector lattice (cf. [9] Th. 13.2).

Usually a complete normed vector lattice is called a Banach lattice in case its norm satisfies the following condition: $|a| \leqq|b|$ implies $\|a\| \leqq\|b\|$ where $|a| \stackrel{\text { def }}{=} a \vee(-a)$. The cone in a Banach lattice is obviously closed. In general, order topology is connected with the norm topology through the closedness of the cone in the following way: if $a_{i} \leqq a i=1,2, \cdots$ and $\lim _{i \rightarrow \infty} a_{i}=x$ then $x \leqq a$, in particular, if $a_{1} \leqq$ $a_{2} \leqq \cdots$ and $\lim _{i \rightarrow \infty} a_{i}=a$ then $a$ is the supremum of $\left\{a_{i}\right\}$. Thus a Banach lattice is quasi- $(o)$-complete. In this connection a quasi-(o)-complete Banach space with a closed generating cone will be called an ordered Banach space.

3. Generating cone. In this section $E$ is a Banach space with a closed cone $K$. First on the ground of Klee's theorem [4] it will be proved that the generating property is equivalent to the stronger one named strict (BZ)-property in Schaefer [9] ((3) in Lemma 1 below).

LEMma 1. The following conditions are mutually equivalent, where $\alpha, \beta$ and $\rho$ are positive constants and $U$ denotes the unit ball of $E$ :

${ }^{2} K^{*}$ satisfies the condition (3), if and only if $K-K$ is dense in $E$. 
(1) $K$ generates $E$,

(2) $(K \cap U-K \cap U)^{-} \supset \alpha U$ where $(\cdot)^{-}$denotes the closure,

(3) $(K \cap U-K \cap U) \supset \beta U$,

(4) any $x \in E$ admits a decomposition $x=a-b$ such that $a, b \in K$ and $\|a\|,\|b\| \leqq \rho\|x\|$.

Proof. (1) $\Longrightarrow(2)$ follows from the second category of $E$, because $E=K-K=\bigcup_{n=1}^{\infty} n(K \cap U-K \cap U)^{-}$. In order to see $(2) \Rightarrow(3)$, let $V \stackrel{\text { def }}{=} K \cap U-K \cap U$ and let $F$ be the subspace generated by $V$. Then on the basis of completeness of $K$, Klee ([4] and [8] Th. 5.5) shows that $F$ is complete under the norm defined by $\|x\|_{V}=\inf \{|\lambda| ; x \in \lambda V\}$. Then (2) shows that under the natural injection of $F$ into $E$ the closure of the image of the unit ball $V$ is a neighborhood of the origin in $E$. A modification of Banach's open mapping theorem (see [2] Chap. I, § 3) yields (3). (3) $\Rightarrow(4)$ and $(4) \Rightarrow(1)$ are trivial.

In the next place quasi-(o)-completeness will be connected with the property named normality in Krein [5] ((3) in Lemma 2 below).

LEMMA 2. The following conditions are mutually equivalent, where $\rho$ is a positive constant:

(1) $E$ is quasi-(o)-complete,

(2) every interval is bounded in norm,

(3) $a \leqq x \leqq b$ implies $\|x\| \leqq \rho \cdot \max (\|a\|,\|b\|)$,

(4) $(U+K) \cap(U-K) \subset \rho U$.

Proof. In order to see $(1) \Rightarrow(2)$, for each $a \in K$ let

$$
V_{a} \stackrel{\text { def }}{=}\{x:-a \leqq x \leqq a\}
$$

and let $F_{a}$ be the subspace generated by $V_{a} . \quad F_{a}$ is complete under the norm defined by $\|x\|_{a}=\inf \{\lambda:-\lambda a \leqq x \leqq \lambda a\}$. In fact, if

$$
\left\|x_{i+1}-x_{i}\right\|_{a}<1 / 2^{i} \quad(i=1,2, \cdots),
$$

by the definition of the norm $\theta \leqq y_{i} \leqq a / 2^{i-1}$ where $y_{i}=x_{i+1}-x_{i}+a / 2^{i}$. Then quasi-(o)-completeness implies the existence of the supremum $y$ of the sequence $\left\{\sum_{i=1}^{n} y_{i}\right\}_{n}$. Put $x=y+x_{1}-a$, then $x-x_{i}$ is the supremum of the sequence $\left\{x_{n}-x_{i}-a / 2^{n-1}\right\}_{n \geq i}$ hence $x-x_{i} \leqq a / 2^{i-1}$, and similarly $x-x_{i} \geqq-a / 2^{i-1}$. This means that

$$
\left\|x-x_{i}\right\|_{a} \leqq 1 / 2^{i-1} \quad(i=1,2, \cdots),
$$

hence $\lim _{i \rightarrow \infty} x_{i}=x$. Since $K$ is closed, as remarked in $\S 2$, the natural injection of $F_{a}$ into $E$ is a closed linear mapping, hence on account of Banach's closed graph theorem (see [2] Chap. I, §3) it is bounded, i.e. $V_{a}$ is bounded in $E$. Now every interval is readily proved to be bounded. 
(3) follows from (2) via a standard argument (see [8] p. 32). (3) $\Rightarrow$ (4) is trivial. $(4) \Rightarrow(1)$ follows from the closedness of an interval and the completeness of $K$.

Before going into the first theorem, let us recall the definition of polar sets. The polar set $A^{0}$ of $A \subset E$ (resp. $\subset E^{*}$ ) is defined by $A^{0}=$ $\left\{f \in E^{*} ; f(x) \leqq 1\right.$ for all $\left.x \in A\right\}$ (resp. $=\{x \in E ; f(x) \leqq 1$ for all $\left.f \in A\}\right)$. For example, $U^{0}$ is the unit ball of $E^{*}$ and $K^{0}=-K^{*}$. The bipolar theorem (see [2] Chap. IV, §1) asserts that (1) $\Gamma(A, B)^{0}=A^{0} \cap B^{0}$ where $\Gamma(A, B)$ denotes the convex hull of $A \cup B$, and (2) if $A \ni \theta$ and $B \ni \theta$ are closed convex sets in $E$ (resp. weakly ${ }^{3}$, i.e. $\sigma\left(E^{*}, E\right)$, closed convex sets in $\left.E^{*}\right)(A \cap B)^{0}=\Gamma\left(A^{0}, B^{0}\right)^{w-}\left(\right.$ resp. $\left.=\Gamma\left(A^{0}, B^{0}\right)^{-}\right)$where $(\cdot)^{w-}$ denotes the weak closure, and (3) if $A$ contains $\theta$ and is a closed convex set in $E$ (resp. weakly closed convex set in $E^{*}$ ), $A^{00}=A$. By the way, remark that the weak compactness of $U^{0}$ and the weak closedness of imply that both $U^{0}+K^{*}$ and $U^{0}-K^{*}$ are weakly closed.

THeorem 1. (1) $K$ generates $E$ if and only if $E^{*}$ is quasi-(o)-complete.

(2) $K^{*}$ generates $E^{*}$ if and only if $E$ is quasi-(o)-complete.

Proof. (1) First remark the formula: $A+B \supset \Gamma(A, B) \supset \frac{1}{2} A+\frac{1}{2} B$ for any convex sets $A \ni \theta$ and $B \ni \theta$. Now the following chain of equivalences is valid, where $\alpha, \beta, \gamma$ and $\rho$ are positive constants:

$K$ generates $E$

$\Longleftrightarrow(U \cap K-U \cap K)^{-} \supset \alpha U$

$\Longleftrightarrow \Gamma(U \cap K,-U \cap K)^{-} \supset \beta U$

$\Longleftrightarrow \Gamma\left(U^{0},-K^{*}\right)^{w-} \cap \Gamma\left(U^{0}, K^{*}\right)^{w-} \subset \gamma U^{0}$

$\Longleftrightarrow\left(U^{0}-K^{*}\right)^{w-} \cap\left(U^{0}+K^{*}\right)^{w-} \subset \rho U^{0}$

$\Longleftrightarrow\left(U^{0}-K^{*}\right) \cap\left(U^{0}+K^{*}\right) \subset \rho U^{0}$ by Lemma 1

by the above remark

by the bipolar theorem

by the above remark

by the weak closedness of $U^{0} \pm K^{*}$

$\Longleftrightarrow E^{*}$ is quasi-(o)-complete by Lemma 2. A proof of (2) is similar and is omitted.

The "only if" part of (1) is essentially known (see [8] p. 46), while (2) is a restatement of Grosberg-Krein's theorem [3] in terms of order properties.

If $E^{*}$ is quasi-(o)-complete, in view of Lemma 2 every interval of $E^{*}$ is bounded in norm and weakly closed, hence weakly compact. Therefore it is readily shown that all the three notions of completeness are the same thing on $E^{*}$.

4. Interpolation property. In this section $E$ is an ordered Banach space. Then Theorem 1 guarantees that $E^{*}$ is also an ordered Banach

${ }^{3}$ The weak topology always refers to the topology $\sigma\left(E^{*}, E\right)$.

${ }^{4}$ Grosberg-Krein's proof differs essentially from ours. 
space. A result of Riesz can be stated as follows (see [8] Th. 6.1): if $E$ is an ordered Banach space with the interpolation property, the dual has the same property, hence by the remark at the end of $\S 3$ it is a vector lattice. In this section the converse will be proved.

Lemma 3. Let $E$ be an ordered Banach space. Then the interpolation property can be derived from the following less restrictive one: for any $\varepsilon>0$ and $a_{i} \geqq b_{j}$ in $E(i, j=1,2, \cdots, n)$ there exist $x \in E$ and $y \in K$ such that $a_{i} \geqq x-y$ and $x \geqq b_{i}(i=1,2, \cdots, n)$ and $\|y\| \leqq \varepsilon$.

Proof. Let $a, b \geqq c, d$. We can successively find $x_{i} \in E$ and $y_{i} \in K$ ( $x_{0}$ and $y_{0}$ being disregarded) such that $a, b, x_{i-1} \geqq x_{i}-y_{i}$ and $x_{i} \geqq c, d$, $x_{i-1}-y_{i-1}$ and $\left\|y_{i}\right\| \leqq 1 / 2^{i}$. Then $-y_{i-1} \leqq x_{i}-x_{i-1} \leqq y_{i}$, hence by Lemma $2\left\|x_{i}-x_{i-1}\right\| \leqq \rho / 2^{i}(i=1,2, \cdots)$. The completeness of $E$ implies that $\lim _{i \rightarrow \infty} x_{i}=x$ exists. Since $\lim _{i \rightarrow \infty} y_{i}=\theta$ and $K$ is closed, we can conclude that $a, b \geqq x \geqq c, d$.

Before going into the second theorem, in order to simplify the notations, for each $A \subset E$ (resp. $\subset E^{*}$ ) define $A^{\ddagger} \stackrel{\text { def }}{=}\left\{f \in K^{*} ; f(x) \geqq 1\right.$ for all $x \in A\}$ (resp. $\stackrel{\text { def }}{=}\{x \in K: f(x) \geqq 1$ for all $f \in A\}$ ). Since $K$ is closed convex, on account of the separation theorem (see [2] Chap. II $\S 3$ ), for $a \in K \quad\{x ; x \geqq a\}=a+K=\{a\}^{\# \#}$.

THEOREM 2. An ordered Banach space $E$ has the interpolation property, if (and only if) the dual $E^{*}$ has the same property.

Proof. Suppose that $E^{*}$ has the interpolation property. It suffices to prove the less restrictive form of the interpolation property for $E$ in Lemma 3. Let $a_{i} \geqq b_{j}(i, j=1,2, \cdots, n)$. All $b_{j}$ may be assumed to be in $K$ because $K$ generates $E$. For any $\varepsilon>0$ and $\gamma>0$

$$
A \stackrel{\text { def }}{=}(1+\varepsilon) \Gamma\left(\left\{b_{i}\right\}^{\sharp} ; i=1,2, \cdots, n\right)
$$

is disjoint from

$$
B \stackrel{\text { def }}{=} \Gamma\left(\left(a_{i}-K\right)^{0} \cap \gamma U^{0} ; i=1,2, \cdots, n\right) .
$$

Otherwise, since $E^{*}$ is an ordered Banach space with the interpolation property, in view of Riesz result stated above the second dual $E^{* *}$ has the same property, therefore there exists $X \in E^{* *}$ such that $a_{i} \geqq X \geqq b_{i}$ $(i=1,2, \cdots, n)$ where $E$ is imbedded into $E^{* *}$ in the natural, linearorder preserving way, then $X(f) \leqq 1$ and $X(f) \geqq 1+\varepsilon$ for $f \in A \cap B$, because, for example, $f$ can be represented as $f=\sum_{i=1}^{n} \alpha_{i} g_{i}$ such that $g_{i} \in\left\{b_{i}\right\}^{\sharp}$ and $\alpha_{i} \geqq 0, \sum_{i=1}^{n} \alpha_{i}=1+\varepsilon$, hence

$$
X(f)=\sum_{i=1}^{n} \alpha_{i} X\left(g_{i}\right) \geqq \sum_{i=1}^{n} \alpha_{i} g_{i}\left(b_{i}\right) \geqq \sum_{i=1}^{n} \alpha_{i}=1+\varepsilon .
$$


This contradiction proves the expected disjointness. Next we shall prove that $A$ is weakly closed and $B$ is weakly compact. Take, for example, the former and suppose $n=2$ for the simplicity sake. On account of Banach's theorem (see [2] Chap. IV, §2) it suffices to prove that

$$
\Gamma\left(\left\{b_{i}\right\}^{\sharp} ; i=1,2\right) \cap \rho U^{0}
$$

is weakly closed for all $\rho>0$. Suppose that a net $\left\{\alpha_{\lambda} f_{\lambda}+\left(1-\alpha_{\lambda}\right) g_{\lambda}\right\}_{\lambda}$ converges weakly to some $h$ in $E^{*}$ where $f_{\lambda} \in\left\{b_{1}\right\}^{\sharp}, g_{\lambda} \in\left\{b_{2}\right\}^{*}, 0 \leqq \alpha_{\lambda} \leqq 1$ and $\left\|\alpha_{\lambda} f_{\lambda}+\left(1-\alpha_{\lambda}\right) g_{\lambda}\right\| \leqq \rho$. Since $E^{*}$ is quasi-(0)-complete, by Lemma $2\left\|\alpha_{\lambda} f_{\lambda}\right\|$ and $\left\|\left(1-\alpha_{\lambda}\right) g_{\lambda}\right\|$ are uniformly bounded. We may assume that $\left\{\alpha_{\lambda}\right\}_{\lambda}$ converges to some $\alpha$. If $0<\alpha<1,\left\|f_{\lambda}\right\|$ and $\left\|g_{\lambda}\right\|$ are uniformly bounded, hence we may even assume that $\left\{f_{\lambda}\right\}_{\lambda}$ and $\left\{g_{\lambda}\right\}_{\lambda}$ converge weakly to some $f$ and to some $g$ respectively because of the weak compactness of $U^{0}$. Since both $\left\{b_{1}\right\}^{\sharp}$ and $\left\{b_{2}\right\}^{\sharp}$ are weakly closed, it follows that $h=\alpha f+(1-\alpha) g$ is in $\Gamma\left(\left\{b_{1}\right\}^{\sharp},\left\{b_{2}\right\}^{\sharp}\right)$. If $\alpha=1$, say, we may assume that $\left\{f_{\lambda}\right\}_{\lambda}$ converges weakly to some $f$ in $\left\{b_{1}\right\}^{*}$, therefore $h \geqq f$, hence $h \in\left\{b_{1}\right\}^{\#}$ by the definition of $\left\{b_{1}\right\}^{\sharp}$. Thus the proof of the weak closedness is over.

Now since $A$ is convex, weakly closed and is disjoint from the convex weakly compact set $B$, by the separation theorem (see [2] Chap. II, $\S 3)$ there exists $c \in E$ such that $f(c) \geqq 1>g(c)$ for all $f \in A$ and $g \in B$. From the remark preceding the theorem and by the bipolar theorem it follows that $(1+\varepsilon) c \geqq b_{i}(i=1,2, \cdots, n)$ and $c \in \bigcap_{1}^{n}\left(a_{i}-K+1 / \gamma U\right)^{-}$. Therefore there exist $\left\{c_{i}\right\}_{1}^{n}$ such that $c+c_{i} \leqq a_{i}$ and $\left\|c_{i}\right\| \leqq 2 / \gamma(i=$ $1,2, \cdots, n)$. Since the cone of $E$ is generating, by Lemma 1 each $c_{i}$ admits a decomposition $c_{i}=d_{i}-e_{i}$ with $d_{i}, e_{i} \in K$ such that

$$
\left\|d_{i}\right\|,\left\|e_{i}\right\| \leqq \rho_{1}\left\|c_{i}\right\|
$$

where $\rho_{1}$ is a positive constant. Finally let $x=(1+\varepsilon) c$ and

$$
y=\varepsilon c+\sum_{i=1}^{n} e_{i}
$$

then $x-y \leqq a_{i}$ and $x \geqq b_{i}(i=1,2, \cdots n)$ and, for some $\rho_{2}>0$,

$$
\|y\| \leqq \varepsilon\|c\|+\sum_{i=1}^{n}\left\|e_{i}\right\| \leqq \varepsilon\left(\rho_{2}\left\|a_{1}\right\|+4 / \gamma\right)+2 \rho_{1} n / \gamma \text {. }
$$

Since $\varepsilon>0$ and $\gamma>0$ are arbitrary, the expected conclusion has been obtained.

\section{REFERENCES}

1. G. D. Birkoff, Lattice theory, 2nd Ed., New York, 1948.

2. N. Bourbaki, Espaces vectoriels topologiques I, II, Paris, 1950, 1953.

3. J. Grosberg and M. G. Krein, Sur la décomposition des fonctionnelles en composantes positives, Dokl. Akad. Nauk SSSR 25 (1939), 723-726. 
4. V, L. Klee, Boundedness and continuity of linear functionals, Duke Math. J., 22 (1955), 263-269.

5. M. G. Krein, Propriétés fondamentales des ensembles coniques normaux dans l'espace de Banach, Dokl. Akad. Nauk SSSR 28 (1940), 13-17.

6. - Sur la décomposition minimale d'une fonctionnelle linéaire en composantes positives, Dokl. Akad. Nauk SSSR 28 (1940), 18-22.

7. H. Nakano, Modulared semi-ordered linear spaces, Tokyo, 1950.

8. I. Namioka, Partially ordered linear topological spaces, Memoirs of Amer. Math. Soc., 24 (1957).

9. H. H. Schaefer, Halbgeordnete lokalkonvexe Vektorräume, I, II, III, Math. Ann., 135 (1958), 115-141; 138 (1959) 254-286; 141 (1960), 113-142.

\section{HOKKAIDO UNIVERSITY}

AND

INDIANA UNIVERSITY 



\section{PACIFIC JOURNAL OF MATHEMATICS}

\section{EDITORS}

\author{
Ralph S. Phillips \\ Stanford University \\ Stanford, California \\ M. G. Arsove \\ University of Washington \\ Seattle 5 , Washington
}

\author{
A. L. Whiteman \\ University of Southern California \\ Los Angeles 7, California \\ Lowell J. Paige \\ University of California \\ Los Angeles 24, California
}
E. F. BECKENBACH
D. DERRY
ASSOCIATE EDITORS
T. M. CHERRY
M. OHTSUKA
H. L. ROYDEN
E. G. STRAUS
E. SPANIER
F. WOLF

\section{SUPPORTING INSTITUTIONS}

\author{
UNIVERSITY OF BRITISH COLUMBIA \\ CALIFORNIA INSTITUTE OF TECHNOLOGY \\ UNIVERSITY OF CALIFORNIA \\ MONTANA STATE UNIVERSITY \\ UNIVERSITY OF NEVADA \\ NEW MEXICO STATE UNIVERSITY \\ OREGON STATE UNIVERSITY \\ UNIVERSITY OF OREGON \\ OSAKA UNIVERSITY \\ UNIVERSITY OF SOUTHERN CALIFORNIA
}

\author{
STANFORD UNIVERSITY \\ UNIVERSITY OF TOKYO \\ UNIVERSITY OF UTAH \\ WASHINGTON STATE UNIVERSITY \\ UNIVERSITY OF WASHINGTON \\ AMERICAN MATHEMATICAL SOCIETY \\ CALIFORNIA RESEARCH CORPORATION \\ SPACE TECHNOLOGY LABORATORIES \\ NAVAL ORDNANCE TEST STATION
}

Mathematical papers intended for publication in the Pacific Journal of Mathematıcs should be typewritten (double spaced), and the author should keep a complete copy. Manuscripts may be sent to any one of the four editors. All other communications to the editors should be addressed to the managing editor, L. J. Paige at the University of California, Los Angeles 24, California.

50 reprints per author of each article are furnished free of charge; additional copies may be obtained at cost in multiples of 50 .

The Pacific Journal of Mathematics is published quarterly, in March, June, September, and December. Effective with Volume 13 the price per volume (4 numbers) is $\$ 18.00$; single issues, $\$ 5.00$. Special price for current issues to individual faculty members of supporting institutions and to individual members of the American Mathematical Society: $\$ 8.00$ per volume; single issues $\$ 2.50$. Back numbers are available.

Subscriptions, orders for back numbers, and changes of address should be sent to Pacific Journal of Mathematics, 103 Highland Boulevard, Berkeley 8, California.

Printed at Kokusai Bunken Insatsusha (International Academic Printing Co., Ltd.), No. 6, 2-chome, Fujimi-cho, Chiyoda-ku, Tokyo, Japan.

PUBLISHED BY PACIFIC JOURNAL OF MATHEMATICS, A NON-PROFIT CORPORATION

The Supporting Institutions listed above contribute to the cost of publication of this Journal, but they are not owners or publishers and have no responsibility for its content or policies. 


\section{Pacific Journal of Mathematics}

\section{Vol. 12 , No. 4 \\ April, 1962}

Tsuyoshi Andô, On fundamental properties of a Banach space with a cone ..... . 1163

Sterling K. Berberian, A note on hyponormal operators ................ 1171

Errett Albert Bishop, Analytic functions with values in a Frechet space . . . . . . . 1177

(Sherman) Elwood Bohn, Equicontinuity of solutions of a quasi-linear equation ............................................ 1193

Andrew Michael Bruckner and E. Ostrow, Some function classes related to the class of convex functions . . . . . . . . . . . . . . . . . . . . . . . . 1203

J. H. Curtiss, Limits and bounds for divided differences on a Jordan curve in the complex domain . . ................................. 1217

P. H. Doyle, III and John Gilbert Hocking, Dimensional invertibility . . . . . . . . 1235

David G. Feingold and Richard Steven Varga, Block diagonally dominant matrices and generalizations of the Gerschgorin circle theorem ................. 1241

Leonard Dubois Fountain and Lloyd Kenneth Jackson, A generalized solution of the boundary value problem for $y^{\prime \prime}=f\left(x, y, y^{\prime}\right) \ldots \ldots \ldots \ldots \ldots \ldots \ldots \ldots \ldots$

Robert William Gilmer, Jr., Rings in which semi-primary ideals are primary. . . . . 1273

Ruth Goodman, K-polar polynomials .......................... 1277

Israel Halperin and Maria Wonenburger, On the additivity of lattice completeness ........................................... 1289

Robert Winship Heath, Arc-wise connectedness in semi-metric spaces . . . . . . . . 1301

Isidore Heller and Alan Jerome Hoffman, On unimodular matrices . . . . . . . . . . . 1321

Robert G. Heyneman, Duality in general ergodic theory . . . . . . . . . . . . . . . 1329

Charles Ray Hobby, Abelian subgroups of p-groups . . . . . . . . . . . . . . . 1343

Kenneth Myron Hoffman and Hugo Rossi, The minimum boundary for an analytic

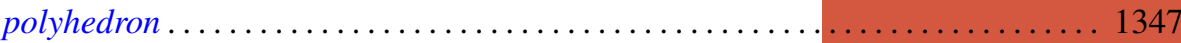

Adam Koranyi, The Bergman kernel function for tubes over convex cones ........ 1355

Pesi Rustom Masani and Jack Max Robertson, The time-domain analysis of a continuous parameter weakly stationary stochastic proces.

William Schumacher Massey, Non-existence of almost-complex structures on

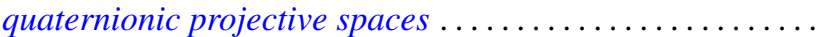

Deane Montgomery and Chung-Tao Yang, A theorem on the action of $\mathrm{SO}(3) \ldots . .1385$

Ronald John Nunke, A note on Abelian group extensions . . . . . . . . . . . . . 1401

Carl Mark Pearcy, A complete set of unitary invariants for operators generating finite $W^{*}$-algebras of type $I$

Edward C. Posner, Integral closure of rings of solutions of linear differential equations.

Duane Sather, Asymptotics. III. Stationary phase for two parameters with an application to Bessel functions.

J. Śladkowska, Bounds of analytic functions of two complex variables in domains

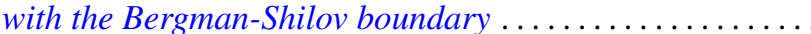

Joseph Gail Stampfli, Hyponormal operators .

George Gustave Weill, Some extremal properties of linear combinations of kernels

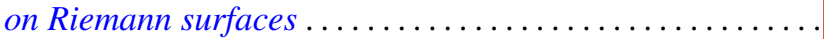

